\title{
The impact of IFRS 8 on segment information quality in the European Union: A multi-dimensional analysis
}

\author{
Ahmed Aboud ${ }^{\mathrm{a}, \mathrm{c} *}$ \\ Clare Roberts ${ }^{b}$ \\ Khaled Hussainey ${ }^{\text {a }}$ \\ ${ }^{a}$ University of Portsmouth, U.K \\ ${ }^{\mathrm{b}}$ University of Aberdeen Business School, Old Aberdeen, U.K \\ ${ }^{c}$ Faculty of Commerce, Beni-Suef University, Egypt
}

\begin{abstract}
We provide comprehensive evidence concerning the impact of IFRS8 on the quality of segmental information disclosed in the annual reports of the largest companies in the European Union. We also assess the impact of using fifteen alternative proxies of segment information quality divided into four dimensions (extensiveness, fineness, variability and consistency). Empirical results reveal that changes, and the strength these changes, following IFRS8 are dependent upon the proxy used. Our results have substantial implications for both policy makers and academic researchers, which are related to the impact of the principle based IFRS8 and the measurement of segment information quality.
\end{abstract}




\section{Introduction}

This study provides empirical evidence on the changes in segment information following the introduction of IFRS8 and addresses the role of the measurement aspect in reshaping the findings of prior research. The IASB issued the principle based IFRS8 in November to unify the reporting approach and arguably to improve quality of segment information ${ }^{1}$. IFRS 8 changed the core principle of reporting segment information from the risk and return approach to the management approach. In particular, it adopts the management approach requiring the disclosure of information through the eyes of the management. This standard led to much debate in the international and EU context. Although the European Parliament (EP) endorsed the standard after scrutiny procedures, there is still much heated debate around the globe on the effectiveness of this approach. For instance, the IASB post implementation review indicates that some investors dispute the management approach, arguing that it may help managers mask or hide loss making and poorly performing segments (IASB 2013).

Further concerns raised around IFRS8 include the potential loss of geographical information, as the new standard no longer requires geographic disclosures as secondary segments. Moreover, users, on average, are worried that IFRS8 may help management to act in their own self-interest and manipulate segment reporting, arguing that stewardship is more difficult and the objectivity of the reported information is questionable when there is a standard based on the management approach (Berger and Hann 2003; ESMA 2011; Crawford et al. 2012). Additionally, several issues under this approach are blurry, such as aggregation guidelines, reconciliation, the chief operating decision-making (CODM) identification, and the use of non-IFRS measurement.

Although prior studies examined the impact of IFRS8 after the adoption of the management approach in the EU (Crawford et al. 2012; Nichols, Street, \& Cereola, 2012; Leung \& Verriest, 2015, André, Filip \& Moldovan 2016), there are still some aspect that required investigation such as the level of cross segment variability and consistency of segment information throughout the annual reports following IFRS8. Hence, this study addresses the quality of the disclosed segment information after the adoption of IFRS8 in the largest EU firms using fifteen proxies casing four dimensions (quantity, fineness, cross segment variability and consistency). By doing so, this study will contribute to the extant literature through providing comprehensive evidence on the disputable standard IFRS8. This large and diverse set of measures provides a clear and comprehensive picture of the quality of segmental information under the management approach. Second, we provide a cross-country European evidence, 'which has rarely been undertaken in the literature to date (La Rosa, Liberatore, Mazzi \& Terzani, 2017:2).

\footnotetext{
${ }^{1}$ It applies to financial years starting on or after January 12009.
} 
However, the question of how to report segment information has been a hotly debated issue. Quality is a tricky concept and its measurement is complex (Cooke 1989). Tsalavoutas, Evans, Smith (2010) argued that cautious should be taken when interpreting the findings of prior studies on compliance with IFRS mandatory disclosure requirement. In addition, Beyer et al. (2010, p. 311) assert that a sensible economic definition and a direct measure of financial reporting quality are missing from the literature. The existing literature introduced various definitions and measures (Nichols, Street, \& Gray, 2000; Berger \& Hann 2003; Emmanuel \& Garrod 2002; Prencipe 2004; Bens \& Monahan 2004; Berger \& Hann 2007; Hope, Thomas, \& Winterbotham, 2006; Tsakumis, Doupnik, \& Seese, 2006; Nichols, Street, \& Cereola, 2012). Nevertheless, it is not clear whether the use of different quality proxies' matters and whether the conclusions drawn are dependent upon the specific quality proxy employed. Thus, this study investigates the disputable issue of quality measurement for segmental information.

The rest of the paper proceeds as follows. Section 2 looks at previous segmental reporting studies. Section 3 describes the methodology. Section 4 deals with the findings, and finally conclusions and recommendations in section 5 .

\section{Literature Review}

Prior segmental reporting studies covered different issues in a number of different contexts. These include segment disclosure practices, incentives/disincentives, and benefits of segment reporting. This section reviews existing segmental reporting studies to highlight how quality is measured and the anticipated impact of a principle based IFRS8.

Prior studies commonly use the quantity of disclosure as a proxy of the quality of disclosures. Typically, a list of possible disclosure items is generated and each type of item disclosed then is awarded a score (Prather Kinsey 2004; Street \& Nichols 2002; Nichols, Street, \& Cereola, 2012). After the adoption of the management approach in the US, prior studies found that while more items per each operating segment are reported, the number of items disclosed per each geographic segment substantially decreased (Nichols, Street, \& Gray, 2000; Hope, Thomas, \& Winterbotham, 2006). In contrast, Crawford et al. (2012) and Nichols, Street, \& Cereola, (2012) found that the number of items disclosed per geographical and business segment has substantially decreased under the management approach using samples from the UK and continental Europe.

Rennie \& Emmanuel (1992) used the consistency concept to measure the quality of segment information arguing that high-quality disclosure only occurs if, in addition, there are comparable disclosures or disclosures that do not change the number of, or the composition of, the segments. 
The findings on consistency after the adoption of IFRS8 are mixed. Crawford et al.'s (2012) results showed inconsistency in the annual reports for both the business and geographic segments. Contrary, Nichols, Street, \& Cereola, (2012) highlighted a high level of consistency in the annual reports after comparing the segmental note with other parts and showed that $96 \%$ of the sample has consistent information. While one part of the reason for the differences may be the different samples, allied with the inevitable subjectivity involved in assessment, it is also not clear if they defined consistency in the same manner.

A huge body of research viewed the level of disaggregation as an appropriate proxy for disclosure quality arguing that the utility of segment information is positively related to the number of segments reported or the disaggregation of the information provided (Bens \& Monahan 2004, Emmanuel et al. 1999). Looking at the number of segments after the introduction of IFRS8, Crawford et al. (2012) and Nichols, Street, \& Cereola, (2012) found an increase in the number of reported segments after the adoption of IFRS8 and a slightly decrease in the number of companies reporting single segments following IFRS8. Likewise, they found that the fineness of geographic information increased after IFRS8 (Crawford et al 2012; Nichols, Street, \& Tarca, 2013; Leung and Verriest 2015; Kang and Gray 2011, Mardini, Crawford, and Power 2012)

Instead of using disclosures quality, a stream of research has used the properties of segmental level earnings information to measure the overall quality of segmental reporting (Wang et al. 2011; Emmanuel \& Garrod 2002; Troberg, Kinnunen, \& Seppänen, 2010; Ettredge et al. 2006; André, Filip, and Moldovan 2016). Troberg, Kinnunen, \& Seppänen (2010) asserted that the diversity in returns and risks across reported segments is a key characteristic of segment reporting and the grounds on which it accomplishes its objectives. While, Ettredge et al. (2006) simply used the difference between maximum and minimum segment ROA (i.e. range) to measure cross segment variability, Wang et al. (2011) recognized the importance of segment level earnings growth information to investors and competitors beyond scaled earnings level information, thereby using the difference between the fastest and the slowest growing segment. Furthermore, André, Filip, and Moldovan (2016) adjusted Ettredge et al.'s (2006) measure by taking into account industry-level profitability and using return-on-assets (ROA) as a comprehensive measure of profitability instead of return on sales. Ettredge et al. (2006) found that cross segment variability in earnings increased significantly following SFAS 131, although the mean number of segments decreased following SFAS 131, suggesting that the inferences about quality are likely to vary depending upon the proxies employed. Using an aggregated measure, (Fakhfakh, Shabou \& Pige, 2017) find that the adoption of IFRS8 has no impact on segment disclosure quality. The aggregated measure includes the number of segments, the extent of information disclosed and the geographic fineness. Our paper will follow these studies and examine the impact of IFRS8 on the properties of segment level earnings information, using a sample from the EU. 
Although a number of studies have examined the impact of IFRS8 in the EU, there is still a need for comprehensive evidence on the quality of information reported under IFRS8 (Crawford et al 2012; Nichols, Street, \& Tarca, 2013; Leung and Verriest 2015; André, Filip, and Moldovan, 2016; Fakhfakh, Shabou \& Pige, 2017). Furthermore, as discussed above, various definitions and measures have employed in the existing literature and the findings are not always consistent. It is not clear whether the use of different segment quality proxies' matters and whether the conclusions drawn are dependent upon the specific quality proxy employed. Therefore, this paper addresses the effectiveness of IFRS8 in improving the quality of segmental reporting in the EU and empirically assess the impact of using fifteen alternative proxies of segment information quality. Fifteen proxies, as will be discussed in next section (3.2), will be examined based on four main dimensions, namely, the extensiveness of disclosures, the fineness of disclosures, the cross segment variability in return, and the consistency of segment information in different parts of the annual reports.

\section{Research Methodology}

\subsection{Sample Size}

This study empirically addresses how measurement instruments affect our conclusions on the quality of segment information and how this could affect the conclusion reached. Moreover, this study provides empirical evidence on the impact of IFRS8 on segment disclosure quality using a sample of EU firms for four consecutive years per each firm (2007-2011). To do so, the top firms in Europe Union based on the Financial Times list as of 30 March 2011 will be used. To achieve consistency, both non-EU companies and the financial sectors excluded. Table (B.2) presents the sample construction process. The final number of firms used in this study is 208 .

\section{Insert Table (B.2)}

The adoption year has been determined based on manual investigation of the annual report. IFRS 8 issued in 2006 and its effective date is the period beginning on or after 1 January 2009. We code the years with four values, pre period one and two (hereafter Pre 2 and Pre 1) to represent the two years before adoption of IFRS 8 for a specific company, and post period one and two (hereafter Post 1 and Post 2) to represent the first and second year of adoption. Thus, the sample consists of 820-year observations from 18 countries distributed across EU countries as shown in Table (B.3) $)^{2}$.

\footnotetext{
${ }^{2}$ The total number of missing observations is 12 , of which six observations are missing. The remaining six observations are unavailable due to that two companies changed to multi and one firm changed to single after the adoption of IFRS8.
} 


\subsection{Segmental information quality measurement: Four dimensions' matrix}

As discussed in section 2, there is no agreement on how to quality of segmental information quality. Therefore, we employ a number of alternative measures to gauge the quality of segmental information classified into four dimensions.

\subsubsection{Segment information quantity}

Measuring the quantity of disclosure has a long history in accounting research as a proxy of information quality based on the proposition that the extent of information positively relates to the quality (i.e Cooke 1989; Meek, Roberts, \& Gray, 1995; Lopes \& Rodrigues 2007). Disclosure indexes have been used to measure to gauge the quality of disclosure and while the amount of space devoted to relevant topics has been used in CSR research e.g. (Beattie, McInnes, \& Fearnley, 2004; Beck, Campbell, \& Shrives, 2010; Jose \& Lee, 2007; Hussainey and Walker 2009).

Our study uses an index to reflect the quantity of segment information by counting the number of items disseminated in the financial statements notes about operating segments. Our index consists of 53 items comprising two sub-indices; the first contains 38 items relevant to operating segments while the second includes 15 items relevant for entity wide disclosures (Appendix 1). The sources of the items are IFRS8, IAS14R and the existing literature on segmental reporting. To minimise the subjectivity of the measurement process, we use the unweighted index with an item scored one if disclosed and zero otherwise, with the exception of reconciliation items, which score as two if detailed items provided. ${ }^{3}$ To minimise applicability problems, the relative disclosure score (RDI) is calculated as the percentage of actual score awarded to the maximum possible score for each company (Cooke, 1989; Meek, Roberts, \& Gray, 1995; Wallace \& Naser, 1995). For example, if there is no difference between the sum of segment revenue and group revenue, the reconciliation item is not applicable and the company not penalized for nondisclosure.

As shown in the index, three possible measures of quantity is used. The first measure is the relative score for the number of items per operating segment (operating segment quantity: OSQ) and the second is the relative score for the number of items per secondary segment (SSQ). SSQ is the entity wide disclosure score (the second category) but excluding three items (sales per

\footnotetext{
3 The Studies that have adopted both the weighted and unweighted indices found that the weighted indices generally did not capture any differences (Prencipe 2004, Robbins and Austin 1986, Adhikari and Tondkar 1992).
} 
product, major customers and matrix format $)^{4}$. The last measure is the total segment information calculated based on the relative score of all the items including the last three items (FSQ).

\subsubsection{Segment disclosure disaggregation}

The objective of segment reporting is to provide users with incremental information beyond firm wide information. Therefore, the disaggregation of segment information is important as well as the quantity of information provided. Finer information is more likely to enable users to evaluate the nature and financial effect of business activities and the economic environment in which they operate. The IASB stressed that financial information is relevant if it can be used in the prediction of firms' future outcomes (IASB, 2010) and prior research theorized that fineness of segment information improves the predictability of earnings and sales information (Hussain 1997; Herrmann \& Thomas 1997).

Therefore, we employ seven different proxies of disaggregation in attempt to operationalize the relevance of information as defined in the conceptual framework of the IASB. Consistent with previous studies (i.e. Crawford et al. 2012; Nichols, Street, \& Gray, 2000), the first three measures simply consider the number of segments: the number of business segments (hereafter NBS), the number of geographic segments (hereafter NGS) regardless of whether they are primary or secondary segments, and the number of individual countries (hereafter NCS).

However, it is not simply the number of countries or segments that is important but also important is the ease of combining this information with information about the operating environment. Therefore, we use two other proxies to measure the quality of geographical segment accounting numbers (i.e. sales). Arguably, of much more importance is the proportion of total sales that is disclose about the individual countries. Country specific information represents the highest possible level of fineness. It is likely to be more important to know that $60 \%$ of sales come from one named country than to know, for a second firm, that each of three named countries account for $10 \%$ of sales. Therefore, this study uses the proportion of total firm sales disclosed by individual country (hereafter the Country Specific Sales, CSS) to measure fineness of geographical disclosures.

While country by country reporting provides the finest and potentially most useful information, there is a variety of alternative levels of desegregation. For instance, sub continental disclosures have privilege over continental or less disaggregated segments. Also, while some companies provide country specific information and at the same time aggregate the remaining results into one segment such as "other", other companies instead report only named continent segments such

\footnotetext{
${ }^{4}$ These three items were excluded because they are not part of the secondary information and to use the score of SSQ to explain the impact of IFRS8 on the quantity of secondary segment information given the heated debate on the impact of IFRS8 on geographical disclosures.
} 
as "Americas" or "Europe". In this case, the overall fineness of segmental reporting may be greater for firms with less country information. Thus, consistent with Kou and Hussain (2007), the fifth proxy used is a comprehensive measure for the fineness of all geographical segments (Geographical Fineness Score GFS) and computed as the sum of individual segment sales divided by total sales multiplied by the appropriated weight for that type of segment:

$$
\sum_{N=1}^{N} \frac{G i^{\prime} \text { s sales }}{T G S} * G W i
$$

Where $\quad \mathrm{N}$ : number of geographical areas/segments

Gi's: revenue for geographic area/segment i

GWi: geographical weight

TGS: total segments/areas revenues

The finest level of disclosure is country, which is weighted by a scale of three, while a scale of two is applied to continent or sub-continent segments such as 'The Americas' or 'North America', a scale of one for multi-continent segments such as 'Europe and Asia' and zero for unspecified segments such as 'other'.

In terms of business fineness, again it is not simply the number of segments but also the disaggregation of revenues cross segments that is important. Thus, consistent with Berger and Hann (2003) the Herfindahl revenues index (HR). Herfindahl revenues index (HR) is the sum of squares of individual segment sales divided by the squared sum of segments sales (Berger and Hann 2003).

$$
\sum_{t=1}^{n} S i^{2} /\left(\sum_{t=1}^{n} S i\right)^{2}
$$

Where

$\mathrm{n}$ is the number of segments

Si is segment i's sales.

In addition to HR, this study calculates the Herfindahl assets (HA) as another measure of business fineness. 


$$
\sum_{t=1}^{n} A i^{2} /\left(\sum_{t=1}^{n} A i\right)^{2}
$$

Where

$\mathrm{n}$ : the number of segments

Ai: segment i's assets.

For HR and HA, the lower the index, the higher the disaggregation; therefore, to provide a more intuitive measure, the disaggregation measure is calculated as one minus the index, therefore the higher the value, the higher the disaggregation.

\subsubsection{Segment information cross variability}

Relevant information is the information that makes a difference in decision-making; therefore, segment information is more useful when each segment is distinct from other segments so that each segment represents activities or environment with quite different risks or returns. Thus, this study uses cross segment variability in return to operationalize the relevance attribute of useful information. We use two proxy to measure cross segment variability; firstly, following Ettredge et al. (2006), we compute the profit range (RANGE) as the absolute difference between the maximum and minimum segment return. An appropriate measure of profitability is the ratio of segment operating profit to segment assets. Operating profit is the common measure of profit used by European firms, thus minimizing the problem of missing data. In addition, it is less prone to allocation problems than other profit measures. The second measure is an extension of this, but considers all segments and is less sensitive to the presence of outliers. The absolute standard deviation of firm's segments returns on assets (SD ROA).

\subsubsection{Segment information consistency}

While the above dimensions are more concerned with the measurement of the fundamental attributes of useful information, the fourth dimension will measure the consistency of segment information throughout the annual report. Although consistency is neither one of the fundamental nor enhancing attributes of useful information, the conceptual framework illustrated that consistency relates to and helps to achieve comparability (IASB, 2010). In addition, it interacts with the other attributes (i.e. relevance and represent faithfully) to contribute to the usefulness of information (IASB, 2010). 
Thus, the fourth dimension measures the consistency of segment information and distinguishes between two sources of inconsistency. Structure inconsistency occurs either when companies report different segments in the OFR, whether this is more or less segments, or when the structure of the segments disclosed in the OFR differs from the segments notes. Although it is obvious that the structure of segment disclosures is not the same throughout the annual report, this measurement does not show if this company provides more or less disaggregated information in the narrative sections compared to the segmental note. Therefore, we use two further measures are used to examine whether narrative sections include the same, more, or less disaggregated information compared to the segmental note. In this case, it is relatively important to distinguish between geographical and business information. Therefore, geographical (business) consistency addresses whether the narrative sections provide the same, more, or less geographical (business) information compared to the segmental note.

To identify structure, business and geographical consistency, we review the narrative sections including the sections such as Management Discussion and Analysis, Shareholder Letters, Organization Structure, Company in Brief, Business at a Glance. For structure consistency, a dichotomous variable with a value of " 0 " if the same number of segments and structure used in both segment footnote and the narrative sections of annual report, and "1" otherwise. For business and geographical consistency, we review the financial review section for additional disaggregation of business and geographical segments. Three alternatives are possible: less indicates that finer information reported in the narrative sections, more implies finer information disseminated in the note, while the same indicates no differences in disaggregation level.

Therefore, as discussed above, we use fifteen proxies of segmental information to measure the quality of financial reporting either in terms of disclosures or accounting numbers. Table (B.1) provides a summary of these proxies classified into the four dimensions as discussed above.

$$
\text { Insert Table (A.1) }
$$

\section{Results and discussions}

\subsection{The impact of IFRS8 on segment information}

\subsubsection{Segment disclosure quantity}

The quantity of information as measured by the operating segment information, secondary disclosures and full segment information significantly decreased after IFR8, as shown in table (B.4). Moreover, the findings reveal that the impact of IFRS 8 on information quantity is higher on secondary information than operating segments disclosures. 


\subsubsection{Segment disclosure disaggregation}

With regard to geographical disaggregation, four proxies are used (table B.5), namely, number of geographic segments (NGS), number of countries (NC), country specific sales information (CSS), and geographic fineness score (GFS), which weights the relative sales of each segment by a weight based on the level of disaggregation. While the above analysis shows a significant drop in the number of items following IFRS8, the findings of geographical fineness proxies reveal that the disaggregation of geographical information substantially increased following IFRS8. The number of geographical segments increased from an average of 4.6 to 5.01 (significant at 5\%). Looking further at the type of disaggregation implies that the average number of countries increases from 1.58 to 2.74 . This increase can also been seen in the total number of countries disclosed by the sample (309 under IAS 14R and 494 and 501 under IFRS8, significant at 1\%). Supporting this, country sales disclosure increased from $33.3 \%$ of total sales to $46 \%$ ( $z=3.7365$ with $\mathrm{p}=0.0002$ ). However, when total geographic fineness is instead considered the change is less; the geographic fineness score (GFS), a more comprehensive measure of disaggregation level increased, from 2.04 to 2.16 (the maximum score is (3) if all sales are reported by country), a change that is now significant at only $10 \%$. This is because many companies that increased country specific disclosures also employ a residual segment titled "others" or similar.

\section{Insert Table (B.5)}

Similarly, as shown in Table (B.6), the average of the three measures (NGS, HR and HA) of business disaggregation increased after the adoption of IFRS8, although the changes are not as great as that found in the US studies or for geographical fineness. The average score of revenue disaggregation, as measured by Herfindahl revenue (HR), slightly increased from 0.55 to 0.57 after the adoption of IFRS8 (significant at 10\%). The asset disaggregation, as measured by Herfindahl assets (HA) results are very similar with an increase in the mean from 0.56 to 0.59 (significant at 5\%). Likewise, the number of segments is finer in the post IFRS8 period; although the change (mean 3.96 and 4.01) is not significant. Further analysis indicates that 23 companies $(11.62 \%)$ decrease the number of segments, whilst 27 companies (13.65\%) increase the number of segments; the largest increase being four segments by one company, and the most frequent increase being one segment (13 companies). In addition, the mean of number of business segment is significantly less than number of geographical segments (average 4.83 vs. 3.97).

Insert Table (B.6)

\subsubsection{Segment information cross variability}


We measure cross segment variability using the range and the standard deviation of firm segments return on assets (SDROA). The two measures indicate only a very small change after the adoption of the management approach. Indeed, both fell slightly as reported in table (B.7), (change was not significant). This is in contrast to US studies Wang et al. (2011) and Ettredge et al. (2006), which found strong evidence that the management approach prompted US companies to report segments exhibiting greater cross segment variability. Thus, it appears that the EU companies reported higher cross segment variability in the pre the management approach. The average variability of EU companies in the two years prior to the management approach is 0.23 compared to the 0.16 reported for US companies in Ettredge et al. (2006) study. In contrast, the means for the two samples are very similar once they both use the management approach.

\section{Insert Table (B.7)}

\subsubsection{Segment information Consistency}

The fourth dimension examines consistency using three measures, namely, structure, business, and geographical consistency. Consistent with findings of geographical and business fineness, the results as reported in table (B.8) indicate that most of the sample (88.17\%) had structure consistency and this increased after IFRS8 from 84\% to 90.36\%, (significant at 5\%). However as also shown in table (B.8), the level of both business and geographical consistency are lower than structure consistency. For geographical consistency, while the majority of the sample (75.17\%) discloses consistently, $19.13 \%$ report finer geographical information in narrative sections, while $5.7 \%$ provide more disaggregated information in the notes. After IFRS 8 , the number of companies with a similar disaggregation level goes up by $3.9 \%$ (significant at $5 \%$ ). This improvement, albeit modest, in geographical consistency is a direct output of the mandatory requirements of country-by-country analysis.

In terms of business consistency, while virtually the same number of reports show consistent business segment information (76.19\%) as geographical segment information, relatively more reports show more fineness in the narrative sections $(20.43 \%)$ and relatively fewer show finer segmental notes $(2.38 \%)$ than was the case for geographic disclosures. However, there are no significant changes in the fineness levels following IFRS8. This is in agreement with Crawford et al. (2012) in that there is still some inconsistency in the annual reports between the segmental note and the narrative sections of the annual report. However, our findings are inconsistent with Nichols, Street, \& Cereola (2012) who found a very high level of consistency throughout the annual report for the sample from Europe, excluding the $\mathrm{UK}^{5}$.

\footnotetext{
${ }^{5}$ These differences explained by the samples composition. For example, the findings show that the level of consistency is $95 \%$ for German firms (not tabulated)
} 


\subsection{Assessing the impact of using alternative proxies for segment information}

Section 4.1 documented mixed evidence, suggesting that IFRS8 has effectively improved disclosure when measured by some of the proxies, while simultaneously harming disclosure when measured by others. This section therefore assesses the potential impact of measurement selection on disclosure quality assessment and on reshaping the findings. Because alternative proxies are used to measure each dimension of quality, the association between the alternative proxies of each dimension is considered followed by a discussion of the association between the four quality dimensions.

Correlation matrix is used and the existence of strong associations between either the dimensions or the proxies for any single dimension imply that it is sufficient to employ only one of the proxies to measure segment disclosures. For instance, if quantity proxies strongly correlate with fineness proxies, it is enough to use one of them to capture both disaggregation and quantity of information. On the other hand, low correlations across proxies are strong evidence to suggest that both measures complement each other to gain a full picture of disclosure practices. The pivotal point here is the strength of the association between proxies rather than the significance level.

\subsubsection{Analysis of the alternative proxies of each dimension of segment information.}

Table (B.9) reports the Pearson correlation coefficients between fifteen proxies divided into four dimensions (extensiveness, fineness, cross segment variability, and consistency) ${ }^{6}$. The first dimension examined is the quantity of disclosure. As shown earlier, the operating segment measure (OSQ) included 38 items whilst the entity wide disclosure (SSQ) included only 15 items. Thus, not surprisingly, the full segment information index correlates more highly with OSQ than SSQ (0.93 vs 0.41$)$. The low correlation between FSQ and SSQ is due to the very low correlation between SSQ and OSQ at only 0.16. Hence, it is clearly not sufficient to use only the full disclosure index; instead, the two sub-components should be used.

\section{Insert Table (B.9)}

The second dimension is the disaggregation of geographical information measured by four proxies, namely, number of geographical segments (NGS), number of countries (NC), country specific sales (CSS) and geographical fineness score (GFS). The four proxies generate six correlations, which are significant at $1 \%$. Consistent with the results of the quantity of disclosure, the extent of correlation varies greatly across various pairings. The lowest correlation is just 0.13 between NGS and CSS. Thus, countries that report less segments, presumably because they are

6 The findings using non-parametric correlation matrix provide the same conclusions. In addition, the findings remain the same when we divide the sample into two periods (Pre and Post IFRS8). 
less international, in turn report a higher percentage of their sales from individual countries, suggesting the necessity of using complex measures that consider the fineness of accounting numbers. In contrast, the number of countries and country specific sales are more highly correlated, but only at 0.54 . The highest correlation is instead between GFS and CSS at 0.72, casting some doubt on the view that a sophisticated measure that takes into account the type of segments disclosed offers much extra information value.

With regard to Herfindhal assets (HA), Herfindhal revenue (HR) and number of business segments (NBS), the findings show that the two complex measures (HR and HA) are highly correlated (0.745) suggesting that they could be substitutes; however, it also suggests that for at least some companies disclosure of both segment assets and segment revenues would be useful. Likewise, the correlations between NBS and both HR and HA are high (0.549 and 0.525) but far from a perfect correlation, suggesting that the employment of different measures could provide a clear picture of segment information quality. Therefore, the use of NBS and either HA or HR will provide better understanding of the business disaggregation quality.

The third dimension examined cross segment variability measured by RANGE and SDROA. The findings against the results of the other dimensions show a very high correlation between the two proxies, at 0.871 , suggesting that it tends not to matter which proxy is used to measure cross segment variability.

The final dimension examined consistency and measured by three proxies, namely, structure, business, and geographical consistency. Frequency table (B.10) shows high associations between the three dimensions but not as high as the association between the proxies of cross segment variability. Of the $87.74 \%$ of reports exhibiting structure consistency, $68.73 \%$ and $68.72 \%$ also exhibited geographical and business consistency. Although this high association suggests a strong possibility of there being substitutes, at least for some companies addressing business or geographical consistency in addition to structure consistency would be useful. Similarly, $58.81 \%$ of the annual reports with geographical consistency also have business consistency, suggesting that either business or geographical consistency could be addressed; there is no obvious benefit from using both. Statistically, Chi square tests support the association between structure consistency and both geographic and business segment consistency, both being significant at 5\%, while the association between geographic and business fineness was significant at $1 \%$.

\subsubsection{The impact of using different dimensions of segment information quality}

As discussed above, while the correlation analysis reveals the necessity of using more than one measure for extent of disclosure, fineness and consistency, it also shows that for cross segment variability one measure is enough. Now, looking at the correlation between the four dimensions 
to investigate whether the four dimensions of segment information quality are highly correlated or not. Perhaps the most striking result when comparing different dimensions is the lack of a strong relationship between the number of items disclosed and any of the other quality dimensions. If the first three columns of table (B.9) are examined, then none of the three disclosure quantity proxies significantly related to the two cross segment variability proxies. Similarly, none is significantly related to Herfindahl assets or consistency measures, while the three measures are significantly related to Herfindahl revenues and number of segments at significant level of 5\%. Although these coefficients are significant, the size of the coefficient is more important in the current context. The highest coefficient is between secondary segment information quantity and number of business segments (0.24) in these three columns; however, it is relatively low and therefore suggests that the number of items disclosed is complementary to the other dimension.

Looking at the relationship between business and geographical fineness indicates a low correlation, although significant. The highest coefficient is 0.21 (HR and NGS) suggesting that the fineness of business and geographical information are complements and a proper fineness measure should consider both. In the same vein, fineness measures (business and geographical) again indicate a low correlation, although significant, with other dimensions of disclosure. The highest coefficient for geographical fineness measures is 0.10 (between CSS and Range) and for business, fineness is 0.16 (between HR and Range). These relatively low correlations suggest that fineness measures may explain the other dimensions but cannot be a substitute for them. Consistent with this, cross segment variability measures weakly correlated with other dimensions, and the only high correlation, again is between Range and HR (0.16). Therefore, the findings suggest that the four dimensions of segment information quality are complements and it is impossible to measure the quality of information using one dimension. These finding explained the results of Fakhfakh et al., (2017) who find that the adoption of IFRS 8 is associated with no change in segment disclosure quality using aggregated measure.

\section{Conclusion}

This paper motivated by the concerns raised about the quality of segment information following the introduction of IFRS8 and the problem of segment information measurement. Although prior studies addressed the impact of IFRS8, measurement problems associated with prior studies make disclosure quality measurement a fertile domain for contribution. This study contributes to the literature in two ways. Firstly, it uses different proxies and four successive years to provide comprehensive evidence on quality of segment information under IFRS8. Secondly, it addresses the impact of measurement selection on segment quality assessment and provides an attempt to 
measure the quality of segment information using the qualitative attributes of useful information as defined in the conceptual framework of the IASB.

This paper provides a mixed evidence on the impact of IFRS8. While disclosure quantity decreases, especially geographic information after IFRS8, the fineness of both geographic and business segment disclosures has instead increased. However, the largest improvement reported in geographical segment disclosures due to the new requirements to disclose sales for individual countries (if material). Additionally, we find to support the need to focus on more than a single dimension of segmental disclosure quality. The findings indicated that, for some dimensions, the use of a different proxy could lead to different conclusions and the non-associations, or the week associations, between the four dimensions clearly suggests that each dimension provides a unique insight into segmental disclosure practices and quality and the

This work has implications for both academia and regulators. While prior studies have employed several of the proxies considered here as alternatives to measure quality, this study suggests that disclosure quality findings may be dependent upon the specific quality measures employed. Therefore, the choice of quality metric should carefully depends upon the objectives of the study and the consequential choice of a relevant quality metric. Alternatively, studies need to explore disclosure using more than a single disclosure metric. These findings are consistent with Tsalavoutas, Evans, and Smith (2010) in that the pivotal of cautious when interpreting the findings of prior studies on compliance with IFRS mandatory disclosure requirements.

Another implication applies to the regulators, in particular those in the EU countries, regarding the impact of high discretion on disclosure practices. We find that at least some firms have used the flexibility offered by the standard to reduce the quality of information provided. It is also clear that the impact of IFRS8 is often quite different from the impact of SFAS 131, suggesting the importance of caution when accepting US standards. 


\section{References}

Aboud, A. \& Roberts, C. (2016). The impact of IFRS 8 on analyst earnings forecast accuracy: EU Evidence. BAFA annual conference, UK.

André, P., Filip, A., Moldovan, R., Segment Disclosure Quantity and Quality under IFRS 8: Determinants and the Effect on Financial Analysts', The International Journal of Accounting (2016), http://dx.doi.org/10.1016/j.intacc.2016.10.008

Beattie, V., McInnes, B., \& Fearnley, S. (2004). A methodology for analyzing and evaluating narratives in annual reports: A comprehensive descriptive profile and metrics for disclosure quality attributes. Accounting Forum, 28(3), 205-236. doi: 10.1016/j.accfor.2004.07.001

Beck, A. C., Campbell, D., \& Shrives, P. J. (2010). Content analysis in environmental reporting research: Enrichment and rehearsal of the method in a British-German context. The British Accounting Review, 42(3), 207-222. doi:10.1016/j.bar.2010.05.002

Bens, D., \& Monahan, S. J. (2004). Disclosure quality and the excess value of diversification. Journal of Accounting Research, 42(4), 691-730. doi:10.1111/j.1475-679X.2004.00154.x

Bens, D.A., Berger, P.G. \& Monahan, S.J. (2011). "Discretionary Disclosure in Financial Reporting: An Examination Comparing Internal Firm Data to Externally Reported Segment Data", The Accounting Review, vol. 86, no. 2, pp. 417. doi: http://dx.doi.org/10.2308/accr.00000019

Berger, P. G., \& Hann, R. (2003). The impact of SFAS no. 131 on information and monitoring. Journal of Accounting Research, 41(2), pp. 163-223. DOI: 10.1111/1475-679X.00100

Berger, P.G. \& Hann, R. (2007). "Segment Profitability and the Proprietary and Agency Costs of Disclosure", The Accounting Review, vol. 82, no. 4, pp. 869-906. doi: http://dx.doi.org/10.2308/accr.2007.82.4.869

Beyer, A., Cohen, D.A., Lys, T.Z. \& Walther, B.R. (2010). "The financial reporting environment: Review of the recent literature", Journal of Accounting and Economics, vol. 50, no. 2-3, pp. 296-343. doi:10.1016/j.jacceco.2010.10.003

Blanco, B., Lara, J., \& Tribo, J., (2015). Segment Disclosure and Cost of Capital”. Journal of Business Finance \& Accounting,42( 3-4), 367-411. DOI: 10.1111/jbfa.12106

Chavent, M., Ding, Y., Fu, L., Stolowy, H. \& Wang, H. (2006). "Disclosure and determinants studies: An extension using the Divisive Clustering Method (DIV)", European Accounting Review, vol. 15, no. 2, pp. 181-218. DOI:10.1080/09638180500253092

Chen, P.F. \& Zhang, G. (2003). "Heterogeneous Investment Opportunities in Multiple-Segment Firms and the Incremental Value Relevance of Segment Accounting Data", The Accounting Review, vol. 78, no. 2, pp. 397-428. DOI: http://www.jstor.org/stable/3203259

Cooke, T. E. (1989). Voluntary corporate disclosure by swedish companies. Journal of International Financial Management \& Accounting, 1(2), 171-195. doi:10.1111/j.1467-646X.1989.tb00009.x

Crawford, L., Extance, H., Helliar, C., \& Power, D. (2012). Operating segments: The usefulness of IFRS 8. Institutional of Certified Accountant in England and Wales, ISBN 978-1-904574-86-6, 1.

Doupnik, T. S., \& Seese, L. P. (2001). Geographic area disclosures under SFAS 131: Materiality and fineness. Journal of International Accounting, Auditing and Taxation, 10(2), 117-138. doi:10.1016/S10619518(01)00040-4

Emmanuel, C. R., \& Garrod, N. (2002). On the relevance and comparability of segmental data. Abacus, 38(2), 215-234. doi:10.1111/1467-6281.00106

ESMA. (2011). "Review of European enforcers on the implementation of IFRS 8 - Operating segments," European Securities and Markets Authority. 
Ettredge, M., Kwon, S., Smith, D., \& Stone, M. (2006). The effect of SFAS no. 131 on the cross-segment variability of profits reported by multiple segment firms. Review of Accounting Studies, 11(1), 91-117. doi:10.1007/s11142-006-6397-9

Fakhfakh, S. K. Shabou, R. M. \&Pige, B. (2017). Determinants of Segmental Reporting Quality? Evidence from EU. Journal of Financial Reporting and Accounting, Forthcoming.

FASB (1997). "Disclosures about Segments of an Enterprise and Related Information. Statement of Financial Accounting Standards No. 131”. Norwalk, CT: FASB, 1997.

Harris, M.S. (1998). "The Association between Competition and Managers' Business Segment Reporting Decisions", Journal of Accounting Research, vol. 36, no. 1, pp. 111-128. doi: 10.2307/2491323

Hayes, R. M., \& Lundholm, R. (1996). Segment reporting to the capital market in the presence of a competitor. Journal of Accounting Research, 34(2), pp. 261-279.

Herrmann, D., \& Thomas, W. B. (1997). Geographic segment disclosures: Theories, findings, and implications. The International Journal of Accounting, 32(4), 487-501. doi:10.1016/S00207063(97)90034-0

Hope, O. K., Thomas, W. B., \& Winterbotham, G. (2006). The impact of nondisclosure of geographic segment earnings on earnings predictability. Journal of Accounting Auditing \& Finance, 21(3), 323.

Hope, O., \& Thomas, W. B. (2008). Managerial empire building and firm disclosure. Journal of Accounting Research, 46(3), 591-626. doi:10.1111/j.1475-679X.2008.00289.x

Hossain, M. (2008). Change in value relevance of quarterly foreign sales data of US multinational corporations after adopting SFAS 131. Review of Quantitative Finance and Accounting, 30(1), 1. doi:10.1007/s11156-007-0040-0

Hussainey, K \&Walker, M. The effects of voluntary disclosure and dividend propensity on prices leading earnings. . Volume 39, 2009 - Issue 1. http://dx.doi.org/10.1080/00014788.2009.9663348

Hussain, S. (1997). The impact of segment definition on the accuracy of analysts' earnings forecasts. Accounting and Business Research, 27(2), 145. DOI: 10.1080/00014788.1997.9729540

IASB 2006, "International Financial Reporting Standard 8 (IFRS 8), Segment Reporting", IASB

IASB. (2013). Post-implementation review: IFRS 8 operating segments.

Jose, A., \& Lee, S. (2007). Environmental reporting of global corporations: A content analysis based on website disclosures. Journal of Business Ethics, 72(4), 307-322. doi:http://dx.doi.org/10.1007/s10551-0069172-8

Kang, H., \& Gray, S J. Segment Reporting Practices in Australia: Has IFRS 8 Made a Difference?. Australian Accounting Review, 23(30, 232-243.DOI: 10.1111/j.1835-2561.2012.00173.x

Kou, W., \& Hussain, S. (2007). Predictive gains to segmental disclosure matrices, geographic information and industry sector comparability. The British Accounting Review, 39(3), 183-195. doi:10.1016/j.bar.2007.05.002

La Rosa, F., Liberatore, G., Mazzi, F. \& Terzani, S. (2017). The impact of corporate social performance on the cost of debt and access to debt financing for listed European non-financial firms. European Management Journal, In press.

Leung, E., \& Verriest, A. (2015). The impact of IFRS 8 on geographical segment information. Journal of Business Finance \& Accounting, 42(3-4), 273-309. doi:10.1111/jbfa.12103 
Lopes, P. T., \& Rodrigues, L. L. (2007). Accounting for financial instruments: An analysis of the determinants of disclosure in the portuguese stock exchange. The International Journal of Accounting, 42(1), 25-56. doi:10.1016/j.intacc.2006.12.002

Mardini G. H. , Crawford. L Power D., (2012). "The impact of IFRS 8 on disclosure practices of Jordanian listed companies", Journal of Accounting in Emerging Economies, 2(1), pp.67-90. DOI http://dx.doi.org/10.1108/20421161211196139

Meek, G. K., Roberts, C. B., \& Gray, S. J. (1995). Factors influencing voluntary annual report disclosures by U.S., U.K. and continental European multinational corporations. Journal of International Business Studies, 26(3), pp. 555-572.

Nichols, N. B., Street, D. L., \& Cereola, S. J. (2012). An analysis of the impact of adopting IFRS 8 on the segment disclosures of european blue chip companies. Journal of International Accounting, Auditing and Taxation, 21(2), 79-105. doi:10.1016/j.intaccaudtax.2012.07.001

Nichols, N. B., Street, D. L., \& Gray, S. J. (2000). Geographic segment disclosures in the United States: Reporting practices enter a new era. Journal of International Accounting, Auditing and Taxation, 9(1), 5982. doi:10.1016/S1061-9518(00)00025-2

Nichols, N.B. \& Street, D.L. (2007). "The relationship between competition and business segment reporting decisions under the management approach of IAS 14 Revised", Journal of International Accounting, Auditing and Taxation, vol. 16, no. 1, pp. 51-68. doi:10.1016/j.intaccaudtax.2007.01.002

Nichols, N. B., Street, D. L., \& Tarca, A. (2013). The impact of segment reporting under the IFRS 8 and SFAS 131 management approach: A research review. Journal of International Financial Management \& Accounting, 24(3), 261-312. doi:10.1111/jifm.12012

Prather Kinsey, J. (2004). "The effect of revised IAS 14 on segment reporting by IAS companies", European accounting review, vol. 13, no. 2, pp. 213. DOI: 10.1080/0963818032000138206

Principe, A. (2004). "Proprietary costs and determinants of voluntary segment disclosure: evidence from Italian listed companies". European Accounting Review, 13(2), 319340.DOI:10.1080/0963818042000204742

Rennie, E.D. \& Emmanuel, C.R. (1992). "Segmental disclsoure practices: Thirteen years on", Accounting and Business research, vol. 22, no. 86, pp. 151. DOI:10.1080/00014788.1992.9729430

Street, D.L. \& Nichols, N.B. (2002). "LOB and geographic segment disclosures: an analysis of the impact of IAS 14 revised", Journal of International Accounting, Auditing and Taxation, vol. 11, no. 2, pp. 91-113. doi:10.1016/S1061-9518(02)00072-1

Street, D.L., Nichols, N.B., \& Gray, S (2000). Segment Disclosures under SFAS No. 131: Has Business Segment Reporting Improved? Accounting Horizons: September 2000, Vol. 14, No. 3, pp. 259285.doi: http://dx.doi.org/10.2308/acch.2000.14.3.259

Tsalavoutas, L. Evans, M. Smith. Comparison of two methods for measuring compliance with IFRS mandatory disclosure requirements. Journal of Applied Accounting Research, 11 (3) (2010), pp. 213-228

Troberg, P., Kinnunen, J., \& Seppänen, H. J. (2010). What drives cross-segment diversity in returns and risks? Evidence from Japanese and U.S. firms. The International Journal of Accounting, 45(1), 44-76. doi:10.1016/j.intacc.2010.01.003

Tsakumis, G.T., Doupnik, T.S. \& Seese, L.P. (2006)."Competitive harm and geographic area disclosure under SFAS 131", Journal of International Accounting, Auditing and Taxation, vol. 15, no. 1, pp. 32-47. doi:10.1016/j.intaccaudtax.2006.01.003

Wang, Q., Ettredge, M., Huang, Y., \& Sun, L. (2011). Strategic revelation of differences in segment earnings growth. Journal of Accounting and Public Policy, 30(4), 383-392. doi:10.1016/j.jaccpubpol.2011.05.001 


\section{Appendix (A)}

\section{Table (A.1) Disclosure index}

Category one: Operating segments (OSQ)
Description of factors used to identify segments
Description of type of products and services offered by each segment
Revenue from external customers
Intersegment revenue
Basis of intersegment revenue pricing
Interest revenue
Interest expense
Net interest income or expense
Depreciation and amortization
Operating costs
Non cash material items (e.g. impairment )
Income tax expense
Share of profit of associates and joint ventures
Segments result (1)
Segments result (2) (some companies present more than profit measure such
as OI, Ebit, NI)
Minority interest or non-controlling interest
Exceptional items
Discontinued operations
Cash per segment

Cash per segment

Detailed cash information ( Investing - operating - financing cash flows )

Current assets

Noncurrent assets

Intangible assets

Investment in associate or/and joint ventures

Total assets

Capital expenditure

Current liabilities

Long term liabilities

Borrowings

Total liabilities

Reconciliation of liabilities

Reconciliation of profit

Reconciliation of revenue

Reconciliation of assets

Number of employees by segment

Performance ratios (profitability ratios)

Production volume information

Research and development expenses

Category two: Entity Segment disclosures

Revenue by destination

Revenue by origin

\section{Source}

IFRS 8 , Para.21

IFRS 8 , Para. 21

IFRS 8 , Para.23

IFRS 8 , Para. 23

IFRS 8 , Para.27a

IFRS 8 , Para.21

IFRS 8 , Para. 21

Pilot study

IFRS 8 , Para.23

Pilot study

IFRS 8 , Para. 23

IFRS 8 , Para.23

IFRS 8 , Para.24a

IFRS 8 , Para. 23

Pilot study

IFRS 8 , Para.24b

Pilot study

Pilot study

Street el al 2002

Street et al 2002

IFRS 8 , Para. 23

IFRS 8 , Para.23

IFRS 8 , Para.23

IFRS 8 , Para.23

IFRS 8 , Para. 23

IFRS 8 , Para. 2

IFRS 8 , Para.21a

IFRS 8 , Para.21a

Pilot study

IFRS 8 , Para.21a

IFRS 8 , Para.27d

IFRS 8 , Para.27b

IFRS 8 , Para.27b

IFRS 8 , Para.27c

Gray et al 1995

Gray et al 1995

Gray et al 1995

Crawford et al 2012

Crawford et al 2012 


\begin{tabular}{|ll|}
\hline Earnings & IAS 14 \\
Current assets & IAS14 \\
Noncurrent assets & IAS 14 \\
Total assets & Pilot study \\
Current liabilities & Pilot study \\
Long term liabilities & Pilot study \\
Borrowing by segments & Pilot study \\
Amortization and depreciation & IAS14 \\
Total liabilities & IAS14 \\
Capital expenditure & IAS14 \\
Sales per product & IFRS 8 \\
Major customers or statement that none exist & IFRS 8 \\
Matrix format & IFRS 8 \\
\hline
\end{tabular}




\section{Appendix (B)}

Table (B.1): Summary of segment information measurement.

\begin{tabular}{|c|c|c|c|}
\hline Dimensions & Measures & Definition & Name \\
\hline \multirow[t]{3}{*}{ 1) Quantity } & Operating segments quantity & $\begin{array}{l}\text { The number of items reported per operating segments measured by } \\
\text { disclosure index }\end{array}$ & OSQ \\
\hline & Secondary segment information & $\begin{array}{l}\text { The number of items reported by secondary segment measured by } \\
\text { disclosure index }\end{array}$ & SSQ \\
\hline & Full segment quantity & $\begin{array}{l}\text { The total number of items reported in the segmental notes measured by } \\
\text { disclosure index }\end{array}$ & FSQ \\
\hline \multirow[t]{5}{*}{ 2) (A) Geographical Fineness } & Number of geographical segments & The number of geographical segments reported by the company & NGS \\
\hline & Number of countries & The number of countries reported by the company & NCS \\
\hline & Country specific sales & $\%$ of sales disclosed on country base (country by country reporting) & CSS \\
\hline & Geographical fineness score & $N$ & GFS \\
\hline & & $\begin{array}{l}\text { Where } \mathrm{N} \text { is the number of geographical areas/segments, Gi's: revenue for } \\
\text { geographic area/segment i, GWi: geographical weight, TGS: total } \\
\text { segments/areas revenues. For geographical weights (GW), a scale of } 3 \text { for } \\
\text { country specific information, scale of (2) is applied to continent or sub- } \\
\text { continent segments such as 'The Americas' or 'North America', a scale } \\
\text { of (1) for multi-continent segments such as 'Europe and Asia' and zero } \\
\text { for unspecified segments such as 'other'. }\end{array}$ & \\
\hline \multirow[t]{3}{*}{ 2) (B) Business fineness } & Number of business segments & The number of business segments reported by the company & NBS \\
\hline & Herfindahl Assets & $\begin{array}{l}\text { The sum of individual segment assets square divided by the sum of } \\
\text { segments assets square: } \\
\qquad \frac{\sum_{\mathrm{i}=1}^{\mathrm{n}} A_{\mathrm{i}}^{2}}{\left(\sum_{\mathrm{i}=1}^{\mathrm{n}} A_{\mathrm{i}}\right)^{2}}\end{array}$ & HA \\
\hline & & where $\mathrm{n}=$ number of segments, and $\mathrm{Ai}=$ segment i's assets & \\
\hline
\end{tabular}




\begin{tabular}{|c|c|c|c|}
\hline & Herfindahl Revenues & $\begin{array}{l}\text { The sum of individual segment revenues square divided by the sum of } \\
\text { segments revenue square: } \\
\qquad \frac{\sum_{\mathrm{i}=1}^{\mathrm{n}} \mathrm{s}_{\mathrm{i}}^{2}}{\left(\sum_{\mathrm{i}=1}^{\mathrm{n}} \mathrm{s}_{\mathrm{i}}\right)^{2}} \\
\text { where } \mathrm{n}=\text { number of segments, and } \mathrm{Si}=\text { segment i's sales }\end{array}$ & HR \\
\hline \multirow[t]{2}{*}{ 3) Cross segment variability } & Range & Highest segment ROA - Lowest segment ROA & RANGE \\
\hline & SD return & Standard deviation of all segments ROA & SDROA \\
\hline \multirow[t]{4}{*}{ 4) Consistency } & Structure consistency & $\begin{array}{l}\text { A dichotomous variable takes (1) if firm "i" provided segment } \\
\text { information with the same structure along the annual report and (0) } \\
\text { otherwise. }\end{array}$ & SC \\
\hline & Business consistency & $\begin{array}{l}\text { A categorical variable with three values. Same: implies the same business } \\
\text { disaggregation along the annual report; Less: implies more business } \\
\text { disaggregation in the narrative sections and More: implies more business } \\
\text { disaggregation in the segmental note. }\end{array}$ & $\mathrm{BC}$ \\
\hline & Geographical consistency & $\begin{array}{l}\text { A categorical variable with three values. Same: implies the same } \\
\text { geographical disaggregation along the annual report; Less: implies more } \\
\text { geographical disaggregation in the narrative sections, and More: implies } \\
\text { more business disaggregation in the segmental note. }\end{array}$ & \\
\hline & & & GC \\
\hline
\end{tabular}

Notes: This table provides a summary of the fifteen proxies of segmental information divided into four dimensions. 
Table (B.2) Sample composition

\begin{tabular}{|lll|}
\hline Initial sample & 500 & $100 \%$ \\
Less & & $23 \%$ \\
Financial sectors & 116 & $14.8 \%$ \\
Non EU companies & 74 & $14.4 \%$ \\
Early adoption & 72 & $2 \%$ \\
Unavailable/non-English/USA format & 10 & $0.04 \%$ \\
Late adoption & 2 & $3.6 \%$ \\
Single segment companies & 18 \\
Final sample & 208 & $41.6 \%$ \\
\hline
\end{tabular}

Table (B.3) Sample distributions across years and country

\begin{tabular}{|lcccc|}
\hline & \multicolumn{4}{c|}{ Number of observations } \\
Country & PRE 2 & PRE 1 & POST 1 & POST 2 \\
\hline Austria & 4 & 4 & 4 & 4 \\
Belgium & 5 & 5 & 6 & 6 \\
Czech Republic & 2 & 2 & 2 & 2 \\
Denmark & 6 & 6 & 7 & 7 \\
Finland & 4 & 4 & 4 & 4 \\
France & 37 & 38 & 39 & 39 \\
Germany & 22 & 22 & 23 & 23 \\
Greece & 3 & 3 & 3 & 3 \\
Hungary & 1 & 1 & 1 & 1 \\
Ireland & 3 & 3 & 3 & 3 \\
Italy & 12 & 12 & 12 & 12 \\
Luxembourg & 1 & 1 & 1 & 1 \\
Netherlands & 9 & 9 & 9 & 9 \\
Poland & 3 & 3 & 3 & 3 \\
Portugal & 5 & 5 & 5 & 5 \\
Spain & 11 & 12 & 12 & 12 \\
Sweden & 20 & 20 & 20 & 20 \\
UK & 53 & 53 & 54 & 54 \\
Total & 201 & 203 & 208 & 208 \\
Percentage & 24.5 & 24.7 & 25.4 & 25.4 \\
\hline & & & & \\
\hline
\end{tabular}

Table (B.2) presents the distribution of the sample across countries and years. PRE1 and PRE2 indicate the last two years before the adoption of IFRS8. POST1 and POST2 indicate the first two years under IFRS8 respectively. 
Table (B.4) the impact of IFRS 8 on the volume of segment disclosure.

\begin{tabular}{|c|c|c|c|c|c|}
\hline & Mean & Median & Max & Min & SD \\
\hline \multicolumn{6}{|l|}{ Pre- IFRS 8} \\
\hline Operating segments information & 0.41 & 0.405 & 0.727 & 0.154 & 0.098 \\
\hline Entity segments information & 0.279 & 0.25 & 0.583 & 0 & 0.119 \\
\hline Full segments information & 0.367 & 0.357 & 0.596 & 0.153 & 0.084 \\
\hline Country Specific disclosures & 0.338 & 0.247 & 1 & 0 & 0.34 \\
\hline \multicolumn{6}{|l|}{ Post-IFRS 8} \\
\hline Operating segments information & 0.392 & 0.385 & 0.727 & 0.13 & 0.114 \\
\hline Enterprise wide information & 0.227 & 0.25 & 0.583 & 0 & 0.123 \\
\hline Full segments information & 0.348 & 0.339 & 0.596 & 0.136 & 0.095 \\
\hline Country Specific disclosures & 0.458 & 0.44 & 1 & 0 & 0.342 \\
\hline \multicolumn{6}{|l|}{ Total } \\
\hline Operating segments information & 0.401 & 0.391 & 0.727 & 0.13 & 0.107 \\
\hline Enterprise wide information & 0.253 & 0.25 & 0.583 & 0 & 0.124 \\
\hline Full segments information & 0.358 & 0.352 & 0.596 & 0.136 & 0.09 \\
\hline Country Specific disclosures & 0.399 & 0.336 & 1 & 0 & 0.346 \\
\hline Significant Test Post vs. Pre & \multicolumn{5}{|c|}{ Mann - Whitney test } \\
\hline Operating segments information & \multicolumn{5}{|c|}{$-2.480 * *$} \\
\hline Secondary segments information & \multicolumn{5}{|r|}{$-7.228 * * *$} \\
\hline Full segments information & \multicolumn{5}{|r|}{$-3.236 * * *$} \\
\hline Country Specific disclosures & \multicolumn{5}{|r|}{$5.275 * * *$} \\
\hline
\end{tabular}

Table (B.4) provides the findings of the impact of IFRS 8 on segment disclosure. Pre IFRS8 represents the average of the two years before the adoption of IFRS8. Post IFRS8 represents the average of the two years after the adoption of IFRS 8.

Table (B.5) An analysis of geographical fineness reported in the segmental note under IAS14 and IFRS8

\begin{tabular}{|cccccc|}
\hline Years / Items & Mean & Median & MAX & MIN & SD \\
\hline PRE 2 & & & & & \\
Number of Geographical Segment (NGS) & 4.55 & 4 & 15 & 0 & 2.36 \\
Number of Countries (NC) & 1.49 & 1 & 11 & 0 & 1.88 \\
Country Specific Sales (CSS) & 0.344 & 0.248 & 1 & 0 & 0.34 \\
Geographical Fineness Score (GFS) & 2.02 & 2 & 3 & 0 & 0.702 \\
\hline Pre 1 & & & & & \\
Number of Geographical Segment (NGS) & 4.6 & 4 & 15 & 0 & 2.47 \\
Number of Countries (NC) & 1.58 & 1 & 11 & 0 & 2.11 \\
Country Specific Sales (CSS) & 0.333 & 0.242 & 1 & 0 & 0.341 \\
Geographical Fineness Score (GFS) & 2.04 & 2.06 & 3 & 0 & 0.704 \\
\hline Post 1 & & & & & \\
Number of Geographical Segment (NGS) & 5.01 & 5 & 15 & 0 & 2.87 \\
Number of Countries (NC) & 2.47 & 2 & 11 & 0 & 2.52 \\
Country Specific Sales (CSS) & 0.46 & 0.431 & 1 & 0 & 0.341 \\
Geographical Fineness Score (GFS) & 2.16 & 2.27 & 3 & 0 & 0.695 \\
\hline Post 2 & & & & & \\
\hline
\end{tabular}




\begin{tabular}{|cccccc|}
\hline Number of Geographical Segment (NGS) & 5.13 & 5 & 15 & 0 & 3.01 \\
Number of Countries (NC) & 2.52 & 2 & 11 & 0 & 2.55 \\
Country Specific Sales (CSS) & 0.455 & 0.441 & 1 & 0 & 0.343 \\
Geographical Fineness Score (GFS) & 2.15 & 2.27 & 3 & 0 & 0.715 \\
\hline Total & & & & & \\
Number of Geographical Segment (NGS) & 4.83 & 4 & 15 & 0 & 2.7 \\
Number of Countries (NC) & 2.02 & 1 & 11 & 0 & 2.33 \\
Country Specific Sales (CSS) & 0.399 & 0.336 & 1 & 0 & 0.346 \\
Geographical Fineness Score (GFS) & 2.09 & 2.16 & 3 & 0 & 0.706 \\
\hline
\end{tabular}

Notes: Table (B.5) presents descriptive statistics of geographical fineness in the segmental note under IAS14 and IFRS8. PRE1 and PRE2 indicate the last two years before the adoption of IFRS8. POST1 and POST2 indicate the first two years under the adoption of IFRS8 respectively.

Table (B.6) An analysis of geographical fineness reported in the segmental note under IAS14 and IFRS8

\begin{tabular}{|lccccc|}
\hline YEARS /ITEMS & Mean & Median & Max & Min & SD \\
\hline Pre 2 & & & & & \\
Herfindahl Revenues & 0.555 & 0.6 & 0.865 & 0.0389 & 0.2 \\
Herfindahl Assets & 0.56 & 0.607 & 0.859 & 0.0161 & 0.189 \\
Number of business & 3.94 & 4 & 9 & 1 & 1.74 \\
Pre 1 & & & & & \\
Herfindahl Revenues & 0.551 & 0.588 & 0.865 & 0.0389 & 0.204 \\
Herfindahl Assets & 0.568 & 0.611 & 0.859 & 0.0161 & 0.197 \\
Number of business & 3.96 & 4 & 9 & 1 & 1.79 \\
Post 1 & & & & & \\
Herfindahl Revenues & 0.572 & 0.627 & 0.865 & 0.0389 & 0.201 \\
Herfindahl Assets & 0.593 & 0.639 & 0.859 & 0.0161 & 0.194 \\
Number of business & 4.01 & 4 & 9 & 1 & 1.79 \\
Post 2 & & & & & \\
Herfindahl Revenues & 0.564 & 0.614 & 0.865 & 0.0389 & 0.204 \\
Herfindahl Assets & 0.576 & 0.634 & 0.85 & 0.0161 & 0.208 \\
Number of business & 3.99 & 4 & 9 & 1 & 1.76 \\
Total & & & & & \\
Herfindahl Revenues & 0.56 & 0.612 & 0.865 & 0.0389 & 0.202 \\
Herfindahl Assets & 0.574 & 0.621 & 0.859 & 0.0161 & 0.197 \\
Number of business & 3.97 & 4 & 9 & 1 & 1.77 \\
\hline
\end{tabular}

Notes: Table (B.6) presents descriptive statistics of business fineness in the segmental note under IAS14 and IFRS8. PRE1 and PRE2 indicate the last two years before the adoption of IFRS8. POST1 and POST2 indicate the first two years under the adoption of IFRS8 respectively. 
Table (B.7): An analysis of cross segment variability in return under IAS14 and IFRS8

\begin{tabular}{|llllll|}
\hline Yrs. & Mean & Median & Max & Min & SD \\
\hline Pre 2 & & & & & \\
Range & 0.242 & 0.162 & 1.35 & 0.008 & 0.227 \\
SDROA & 0.114 & 0.076 & 0.746 & 0.006 & 0.109 \\
Pre 1 & & & & & \\
Range & 0.248 & 0.15 & 1.35 & 0.008 & 0.275 \\
SDROA & 0.127 & 0.0768 & 0.746 & 0.006 & 0.144 \\
Post 1 & & & & & \\
Range & 0.231 & 0.157 & 1.35 & 0.008 & 0.232 \\
SDROA & 0.11 & 0.0732 & 0.746 & 0.006 & 0.114 \\
Post 2 & & & & & \\
Range & 0.23 & 0.158 & 1.35 & 0.011 & 0.235 \\
SDROA & 0.106 & 0.0726 & 0.746 & 0.007 & 0.108 \\
Total & & & & & \\
Range & 0.238 & 0.156 & 1.35 & 0.008 & 0.243 \\
SDROA & 0.115 & 0.0751 & 0.746 & 0.006 & 0.12 \\
\hline
\end{tabular}

Notes: Table (B.7) presents descriptive statistics of cross segment variability in return under IAS14 and IFRS8. Range is the difference between the largest and smallest segment ROA. SDROA is the standard deviation of firm segments ROA. PRE1 and PRE2 indicate the last two years before the adoption of IFRS8. POST1 and POST2 indicate the first two years under the adoption of IFRS8, respectively.

Table (B.8): An analysis of segment information consistency under IAS14 and IFRS8

\begin{tabular}{|llll|}
\hline Types of consistency & $\%$ & $\%$ & $\%$ \\
Structure consistency & Pre IFRS8 & Post IFRS8 & Total (Four years) \\
Same & 84.9 & 90.36 & 88.17 \\
Business consistency & & & \\
SAME & 77.01 & 74.87 & 76.19 \\
MORE & 20.86 & 22.51 & 21.43 \\
LESS & 2.14 & 2.62 & 2.38 \\
Geographical consistency & & & \\
SAME & 74.18 & 77.13 & 75.17 \\
MORE & 20.88 & 16.49 & 19.13 \\
LESS & 4.95 & 6.38 & 5.7 \\
\hline
\end{tabular}

Notes: Table (B.8) presents an analysis of structure, business, and geographical consistency in return under IAS14 and IFRS8. Same implies consistent information throughout the annual report. Less indicates that finer information is reported in the narrative sections, more implies finer information is disseminated in the notes. PRE indicates the last year before the adoption of IFRS8. POST indicates the first year under IFRS8. 
Table (B.9): Pearson's correlation between alternative proxies of each dimension of quality

\begin{tabular}{|c|c|c|c|c|c|c|c|c|c|c|c|c|c|c|c|}
\hline Disclosure Proxies & osa & ssa & FSQ & NGS & NC & css & GFS & NBS & HA & HR & RANGE & SDROA & sc & $\mathrm{BC}$ & GC \\
\hline \multicolumn{16}{|l|}{ Dimension one : Quantity } \\
\hline 1-Operating segments information (OSQ) & 1 & & & & & & & & & & & & & & \\
\hline 2-Secondary wide disclosure (SSQ) & $0.1665 * * *$ & 1 & & & & & & & & & & & & & \\
\hline 3-Full segments information (FSQ) & $0.9395 * * *$ & $0.4179 * * *$ & 1 & & & & & & & & & & & & \\
\hline \multicolumn{16}{|l|}{ Dimension Two : Geographical fineness } \\
\hline 4-Number of geographical segments (NGS) & $0.1120^{* * *}$ & $-0.07^{*}$ & $0.0877^{* *}$ & 1 & & & & & & & & & & & \\
\hline 5- Number of countries (NC) & $0.0939 * * *$ & $-0.1129 * * *$ & $0.0685^{*}$ & $0.6716^{* * *}$ & 1 & & & & & & & & & & \\
\hline 6-Country specific disclosures (CSS) & $0.0882^{* *}$ & $-0.0842^{* *}$ & $0.0812^{* *}$ & $0.1394^{* * *}$ & $0.5441^{* * *}$ & 1 & & & & & & & & & \\
\hline 7- Geographical fineness score (GFS) & 0.0533 & $0.0751^{* *}$ & $0.0880^{* *}$ & $0.3453^{* * *}$ & $0.4280^{* * *}$ & $0.7276^{* * *}$ & 1 & & & & & & & & \\
\hline \multicolumn{16}{|l|}{ Dimension two : Business fineness } \\
\hline 8-Number of segments (NBS) & $0.1360^{* * *}$ & $0.2456 * * *$ & $0.1545^{* * *}$ & $0.0728^{* *}$ & $0.0932^{* *}$ & $0.1541^{* * *}$ & $0.1280^{* * *}$ & & & & & & & & \\
\hline 9-Herfindahal Revenue (HR) & 0.0041 & 0.0581 & 0.0115 & $0.2149 * * *$ & $0.1261^{* * *}$ & $0.0624^{*}$ & $0.0909 * *$ & $0.5256 * * *$ & 1 & & & & & & \\
\hline 10-Herfindahal Assets (HA) & $0.0979 * *$ & $0.0883^{* *}$ & $0.0834^{* *}$ & $0.1720^{* * *}$ & $0.1353^{* * *}$ & $0.1326^{* * *}$ & $0.1589 * * *$ & $0.5498^{* * *}$ & $0.7450^{* * *}$ & & & & & & \\
\hline \multicolumn{16}{|l|}{ Dimension Three : Cross segment variability } \\
\hline 11- Range & -0.0029 & 0.0264 & -0.014 & 0.0518 & $0.0906^{* *}$ & $0.1000^{* * *}$ & $0.0858^{* *}$ & -0.014 & $0.1618^{* * *}$ & $0.1466^{* * *}$ & 1 & & & & \\
\hline 12- Standard deviation of ROAs (SDROAs) & -0.026 & 0.011 & -0.0311 & 0.0115 & 0.0562 & 0.0423 & 0.0328 & -0.0311 & 0.0502 & 0.0247 & $0.8716^{*}$ & 1 & & & \\
\hline \multicolumn{16}{|l|}{ Dimension four : Consistency } \\
\hline 13- Structure consistency (SC) & -0.053 & -0.0114 & -0.0649 & -0.0203 & -0.0322 & 0.0076 & 0.0089 & -0.0649 & -0.0398 & -0.0202 & 0.0254 & $0.0948^{* *}$ & 1 & & \\
\hline 14- Business finenesss consistency (BC) & -0.0264 & -0.0288 & -0.0371 & 0.0294 & -0.0125 & $-0.0946 * *$ & -0.0412 & -0.0371 & 0.0126 & -0.0636 & -0.0388 & 0.0556 & $0.1936 * * *$ & 1 & \\
\hline 15- Geographical fineness consistency (GC) & -0.0076 & $0.0687^{*}$ & -0.0032 & 0.0178 & 0.0411 & 0.0172 & 0.0003 & -0.0032 & 0.0028 & 0.0675 & 0.0026 & $0.0797 * *$ & $0.1815^{* * *}$ & $0.1686 * *$ & \\
\hline
\end{tabular}

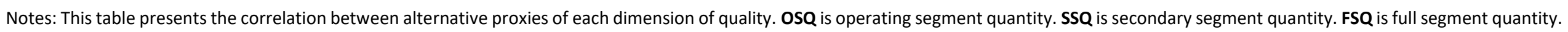

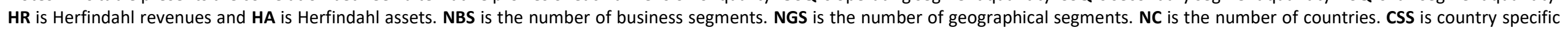

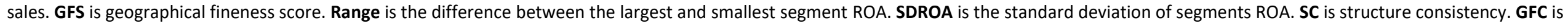
geographical fineness consistency and BFC is business fineness consistency. 
Table (B.10): Frequency tables of the association between structure consistency and both geographical and business consistency

\begin{tabular}{|lllll|}
\hline Structure Consistency & \multicolumn{5}{c|}{ Geographical Consistency } \\
\hline & $\%$ & $\%$ & $\%$ & Total \\
& Same & More & Less \\
$\mathbf{0}$ & 68.73 & 14.46 & 4.55 & 87.74 \\
$\mathbf{1}$ & 6.2 & 4.96 & 1.1 & 12.26 \\
TOTAL & 74.93 & 19.42 & 5.65 & 100 \\
\hline \multicolumn{5}{c}{ Business Consistency } \\
\hline $\mathbf{0}$ & 68.72 & 18.18 & 0.8 & 87.7 \\
$\mathbf{1}$ & 7.22 & 3.48 & 1.47 & 12.17 \\
TOTAL & 76.07 & 21.66 & 2.27 & 100 \\
\hline
\end{tabular}

Table B.10, presents the relation between structure consistency and both business and geographical consistency. (0) implies that segmental note is consistent with other parts of the annual report and (1) implies that the segmental note is not consistent with other parts of the annual report. Table (B.11) presents the relation between business and geographical consistency. Less indicates that finer information reported in the narrative sections, more implies finer information disseminated in the notes, while the same indicates no differences in disaggregation.

Panel (B.11): Frequency tables of the association between geographical consistency and business consistency

\begin{tabular}{|lcccc|}
\hline \multicolumn{5}{c|}{ Business Consistency } \\
\hline Geographical Consistency & Same & More & Less & Total \\
\hline Same & 58.81 & 14.63 & 0.85 & 74.29 \\
More & 13.35 & 5.82 & 0.57 & 19.74 \\
Less & 3.98 & 0.85 & 1.14 & 5.97 \\
TOTAL & 76.14 & 21.31 & 2.56 & 100 \\
\hline
\end{tabular}

